\title{
Spatial properties of a forest buffalo herd and individual positioning as a response to environmental cues and social behaviour
}

\author{
Mario Melletti · M. M. Delgado · Vincenzo Penteriani • \\ Marzia Mirabile · Luigi Boitani
}

\begin{abstract}
Many animals aggregate into organized temporary or stable groups under the influence of biotic and abiotic factors, and some studies have shown the influence of habitat features on animal aggregation. This study, conducted from 2002 to 2004 in the Dzanga-Ndoki National Park, Central African Republic, studied a herd of forest buffaloes (Syncerus caffer nanus) to determine whether spatial aggregation patterns varied by season and habitat. Our results show that both habitat structure and season influenced spatial aggregation patterns. In particular, in open habitats such as clearings, the group covered a larger area when resting and was more rounded in shape compared to group properties noted in forest during the wet season. Moreover, forest buffaloes had a more aggregated spatial distribution when resting in clearings than when in the forest, and individual positions within the herd in the clearing habitat varied with age and sex. In the clearings, the adult male $(n=24)$ was generally, on most occasions, located in the centre of the herd $(n=20)$, and he was
\end{abstract}

M. Melletti (\&) · L. Boitani

Department of Animal and Human Biology, University of Rome

“La Sapienza”, Vle. dell’Università 32, 00185 Rome, Italy

e-mail: mario.melletti@yahoo.it

M. M. Delgado · V. Penteriani

Department of Conservation Biology, Estación Biológica

de Doñana, CSIC, Avda. de María Luisa s/n. Pabellón del Perú,

41013 Seville, Spain

\section{Penteriani}

Finnish Museum of Natural History, Zoological Museum, University of Helsinki, 00014 Helsinki, Finland

M. Mirabile

High Institute for Environmental Protection and Research, Via Brancati 48, 00144 Rome, Italy observed at the border only four times. In contrast, females $(\mathrm{n}=80)$ occupied intermediate $(\mathrm{n}=57)$, peripheral $(n=14)$ and central positions $(n=9)$ within the group. Juveniles $(n=77)$ also occurred in intermediate $(n=64)$ and peripheral positions $(n=13)$. Based on these results, we concluded that habitat characteristics and social behaviour can have relevant effects on the spatial distribution of animals within a group.

Keywords Animal aggregation - Forest buffalo · Group structure · SADIE - Spatial pattern · Syncerus

\section{Introduction}

A wide range of animals, including birds, ungulates and a variety of terrestrial and marine vertebrates and invertebrates aggregate into organized temporary or permanent groups such as flocks, herds and schools (e.g. Gueron et al. 1996; Grear and Schmitz 2005; Morrell and James 2008).

Many efforts have been made to improve our understanding of the physical features of the landscape as principal influences on animal aggregation. Exogenous factors, such as the presence of predators (Hamilton 1971; Beecham and Farnsworth 1999; Krause and Ruxton 2002; Hoare et al. 2004; Ioannou et al. 2007; Ioannou and Krause 2008) or various conditions (e.g., time of day, season, temperature, the probability of food acquisition, synchronizing activity budgets: Perry 1995a; Parrish and Hamner 1997; Ruckstuhl 1999; Chesson 2000; Gerard et al. 2002; Korte 2008b) are common mechanisms that can trigger animal aggregation, increase group size and cohesion and decrease attack success. In several species (e.g. in ungulate herds: Focardi and Pecchioli 2005; geese and wading birds: Van Gils and Piersma 2004), individual aggregation 
represents a trade-off between a tendency to concentrate as a behavioural mechanism against predation and a tendency to disperse to minimize foraging competition. For example, in small populations of ungulates, the need to reduce predation risk by forming large groups may override the need to optimize foraging behaviour by forming peer groups (Ruckstuhl and Festa-Bianchet 2001).

Animal aggregations can also result from endogenous factors, such as gregarious behaviour (Grear and Schmitz 2005) and conspecific attraction (Lagory 1985; Turkalo and Fay 2001; Gerard et al. 2002; Lingle 2003), that are carried out within a complex of different activities (Rands et al. 2006; Sumpter 2006).

Previous studies have shown that several key factors act as external selection pressures to determine both the positions of individuals within the group and the group structure (e.g. Magurran 1993; Parrish and Hamner 1997; Ruckstuhl 1998; Krause and Ruxton 2002; Ruckstuhl and Kokko 2002; Turner et al. 2005; Hay et al. 2008; Korte 2008b; Morrell and Romey 2008). These factors include feeding and foraging efficiency, energy expenditure, the time spent on vigilance behaviour, predation risk, group size, sexual segregation and reproductive opportunities. For example, different kinds of segregations, which can occur and vary throughout the year, have been observed in Cape buffalo (Syncerus caffer caffer) (Turner et al. 2005). In this species, sexual segregation can occur when males and females use different habitats (habitat segregation), occupy exclusive ranges (spatial segregation) or occur in separate social groups (social segregation; Turner et al. 2005).

The forest buffalo (Syncerus caffer nanus) is one of the least known large African forest mammals, with limited and patchy distribution in the Congo basin. It is the only forestdwelling subspecies of the African buffalo (Syncerus caffer), of which the other four subspecies inhabit mainly savannah lands (Sinclair 1977; Mloszewski 1983; Prins 1996; Wilson and Reeder, 2005). Present knowledge on the ecology and behaviour of this mammal is very limited. To the best of our knowledge, the investigation reported here is the first to take into account spatial aggregation patterns in the forest buffalo. We have studied a herd of buffaloes (for more details, see Melletti et al. 2007b; Korte 2008a; Melletti 2008) with the aim of exploring social behaviour when the herd was resting in the forest or in open habitats (i.e. clearings) during the wet and dry seasons, respectively. In particular, we investigated whether the spatial properties of the herd varied by season and habitat. If animal grouping behaviour depends on local cues, we predicted that the spatial structure, resting pattern and size (i.e. the area used by the herd) of the forest buffalo herd should change in response to environmental cues, such as habitat type or season. For example, the presence of obstructing elements in the forest habitat (e.g. trees, lianas and dense vegetation) could influence group shape and nearest neighbour distances. In comparison, in an open habitat such as clearings, the distance at which individuals perceive one another could increase the group size, allowing animals to form larger herds when resting (Gerard et al. 2002; Lingle 2003). We also examined whether individuals with different age/sex classes occupied particular spatial positions within their social group. We further predicted that if social factor can structure animal aggregations, the adult male could occupy the centre of the herd, whereas other members (i.e. females and juveniles) may occupy less favourable places within the herd.

\section{Materials and methods}

Study area and data collection

From 2002 to 2004 we studied buffalo herd behaviour in the rainforest of the Bai-Hokou area $\left(2^{\circ} 55^{\circ} \mathrm{N}, 16^{\circ} 20^{\circ} \mathrm{E}\right)$ in the Dzanga sector of the Dzanga-Ndoki National Park (Central African Republic; more details in Blom 2001; Blom et al. 2001; Melletti et al. 2009). We measured the location and spatial distribution of the buffaloes at resting sites in forest and clearing habitats during both seasons. Observations were made at 45 resting sites of the same herd in two different habitat types and seasons: clearings ( $n=24 ; 17$ during the wet and seven during the dry season) and forest ( $\mathrm{n}=21 ; 13$ during the wet and eight during the dry season). The 45 resting places correspond to 45 different days. During the 2-year study period we actually identified more than 45 resting sites, but we excluded from the analyses (1) all sites corresponding to a low number of individuals and (2) those forest sites in which "beds" (a bed is a clearly visible depression on the ground created by the resting buffalo) exceeded the number of individuals in the herd (i.e. simply corresponding to buffalo that changed position during the night). During the study period the herd size grew from 16 to 24 individuals (Melletti et al. 2007b).

Each of the direct observations of the herd resting in the clearing were conducted by scan sampling of the group for a period of 30-min continuous scanning, following similar procedures described in Altmann (1974) and Fragazy et al. (1992). During the scan we identified all visible individuals, and we collected data on interindividual distances. The locations of buffaloes when resting were determined at the beginning of the observation period. In the case of individuals standing up or changing position during the observations, we waited until all buffaloes were lying down before starting the scan sampling. These observations were always recorded in the same clearing even if the buffaloes used other clearings. There are about 19 rain-forest clearings in the Bai-Hokou study area, ranging in size between 0.4 and 5.5 ha (Blom 2001). 
Daily observations were equally distributed between mornings (0700-1200 hours) and afternoons (12011700 hours), and the number of days in the field were equivalent in the wet and dry seasons. On average, we recorded data on approximately 4 days per week. Observations were conducted on foot using binoculars (109), a digital camera (zoom 109; pictures were used only for the identification of individual buffaloes) and a telemeter (49, range $600 \mathrm{~m}$ and accuracy $\pm 1 \mathrm{~m}$ ). Direct measurements were made at the resting sites to calculate distances between individuals as follows: the observer positioned himself relative to the side of each herd to form a right-angle, and then the distances between the observer and two buffaloes were measured by telemeter. The distance between the two individuals was then calculated as the third side of the right triangle. This triangulation was accurate to $\pm 1 \mathrm{~m}$. Distances between individuals in the forest and clearing resting places were also determined by measuring distances between beds when buffaloes left them (see Melletti et al. 2007a for more details). We found similar distances, in the same clearing resting place, when we compared individual distances using the telemeter and the bed distances using a tape when buffaloes left the site. Moreover, we selected only forest resting places in which the beds did not exceed the number of buffaloes in the herd.

When individual buffaloes were using the forest, only indirect location of buffalo resting places was possible. In this case it was not possible to relate an individual's position within the herd to both sex and age classes. We found the resting places by following the buffalo's trails by a native guide who is an expert in animal tracks and we considered each observation as: (a) nocturnal, when we observed the herd moving inside the forest just before sunset and, the day after, we found a resting place by following the traces left by the herd during such nocturnal movement; and (b) diurnal, when we directly observed resting buffaloes during diurnal observations in the clearings (Melletti et al. 2007a).

In the clearing habitat we used the criteria of Pineaar (1969) and Prins (1996) to determine the age and sex of individuals. Although the body size, shape, and head and horn size of adult forest buffaloes are more similar between sexes than in the Cape buffalo, it was possible to distinguish males from females.

We used ArcView v. 3.2 geographic information system (GIS) software to create map representations $(1: 10,000)$ of the different resting places.

We characterized the spatial properties of the herd by estimating the following parameters

\section{(a) Area covered by the herd}

We used animal movement extension (Hooge and Eichenlau 1997) to calculate noncircular home ranges employing the Jennrich-Turner estimator (Jennrich and Turner 1969). The Jennrich-Turner method has the advantage of speed and simplicity. The main utility of this program lies in developing statistically simple home range-habitat models and in comparison with home range estimates using this method in other studies (Hooge and Eichenlau 1997). In this approach, noncircular areas (of elliptic shape) represent the share of total area use based on the activity seen. The Jennrich-Turner estimator assumes that the spatial model for the home range is a bivariate normal probability distribution, allowing inclusion of a selected percentage of the observations in an effort to limit outliers. We defined three tolerance ellipses (E95, E90, and E50) comprising 95, 90, and 50\% of individuals, respectively.

(b) Herd structure

We estimated the degree of elongation (DEG) of the herd by dividing the lengths of the $\mathrm{x}$ and $\mathrm{y}$ axes of the total E95 ellipse (see Focardi and Pecchioli 2005 for more details), where DEG $=1$ indicates a perfectly circular group, and DEG $=0$ indicates that the group formed a perfectly straight line.

(c) Spatial pattern of the herd

We analyzed the spatial pattern of individuals within the herd by measuring the pattern of distribution compared to extreme arrangements (random, regular, and aggregated). We used the SADIE system (Spatial Analysis by Distances IndicEs: Perry 1995b; Perry et al. 1996) to assess the degree of nonrandomness in the two- dimensional spatial patterns of populations. Specifically, this method equates the degree of spatial pattern in an observed arrangement of counts to the minimum effort that individuals would need to move to a regular pattern (Perry 1998; Perry et al. 1999). The spatial pattern was used to compare the observed counts with other arrangements (that is, crowded or aggregated, or random or regular, spatial patterns; Perry 1995a) to obtain three different indices: (1) $I_{a}$ (based on distance to regularity); $I_{a} \Gamma 1$ for individuals showing an aggregated spatial pattern; (2) $I_{a}=1$ for random aggregation patterns; (3) $I_{a} \backslash 1$ for individuals adopting regular distribution patterns; (4) J (based on distance to crowding); J $\mathbf{E} 1$ indicates that individuals are aggregated; (5) $\mathrm{J}=1$ indicates a random pattern; (6) $\mathrm{J} \backslash 1$ indicates a regular spatial pattern; and (7) V (based on degree of clustering), which provides quantitative information on the spatial aggregations. An aggregation is considered random until the threshold $\mathrm{V}=1$, and clustered when $\mathrm{V}=1.5$.

We analyse individuals' position within the herd to study the role of social factor in determining the spatial position of individuals within a group. Following 
Focardi and Pecchioli (2005), we used the calculated E95, E90, and E50 tolerance ellipses to determine the position of each individual within the group. We defined three classes: (1) central, for animals within the E50 ellipse; (2) medium, for animals within the E90 ellipse; and (3) far, for animals within the E95 ellipse. Only in the clearing habitat type it was also possible to relate an individual's position within the herd to both sex and age classes.

\section{Statistical analyses}

To explore how environmental cues (i.e., habitat type and season) affected the herd area, the spatial structure and the pattern of the herd, we used Generalized Linear Mixed Models (GLMM, McCullagh and Nelder 1989). Mixedeffects models permit both the fixed and random effects to be fitted in one analysis. Because we had repeated measures data of a single herd over time and to avoid pseudo replication problems, the different resting places maps were considered as a random effect.

We used $v^{2}$ tests to assess whether individuals of different age/sex classes had a specific predilection for a spatial position within their social group.

We also included habitats and seasons as explanatory variables in the Mixed Models to analyze whether environmental cues had an effect on the number of individuals in each position within the herd. Statistical significance was set to $\mathrm{P} \backslash 0.05$.

\section{Results}

Area and herd structure

Some environmental cues affected the spatial properties of the forest buffalo herd. The area covered by the herd was affected by the habitat type $(\mathrm{F}=6.11, \mathrm{P}=0.02)$. The herd area was larger when resting in clearings (Fig. 1a; E95 clearings: $\bar{x}=406.6 \pm 227.0 \mathrm{~m}^{2}$ ) than when resting in forest (Fig. 1b; E95 forest: $\bar{x}=396.5 \pm 325.8 \mathrm{~m}^{2}$ ). Finally, DEG was also affected by the habitat type $(F=18.05$, $\mathrm{P} \backslash 0.001)$. GLMM results showed that the herd was more rounded in clearing habitat (Fig. 1a; DEG clearings: $_{\text {a }}$; $\overline{\mathrm{x}}=0.83 \pm 0.08$ ) than in forest (Fig. $1 \mathrm{~b} ; \mathrm{DEG}_{\text {forest: }}$ : $\overline{\mathrm{x}}=0.68 \pm 0.08$ ). None of spatial pattern indices showed evidence for a relationship with environmental cues. However, the buffaloes seemed to have a more aggregated spatial distribution when resting in clearings $\left(\mathrm{J}_{\text {clearing: }}\right.$ : $\overline{\mathrm{x}}=0.84 \pm 0.63)$ during the dry season $\left(\mathrm{J}_{\mathrm{dry}}: \overline{\mathrm{x}}=\right.$ $0.83 \pm 0.58)$ than during the wet season $\left(\mathrm{J}_{\text {wet }}: \overline{\mathrm{x}}=\right.$ $0.58 \pm 0.64)$. In contrast, individuals were randomly

\section{a. Clearings habitat}

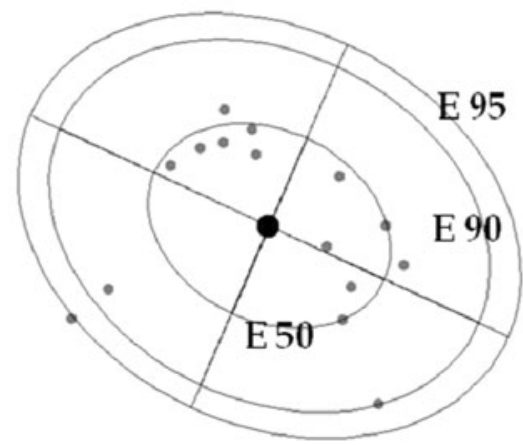

b. Forest habitat

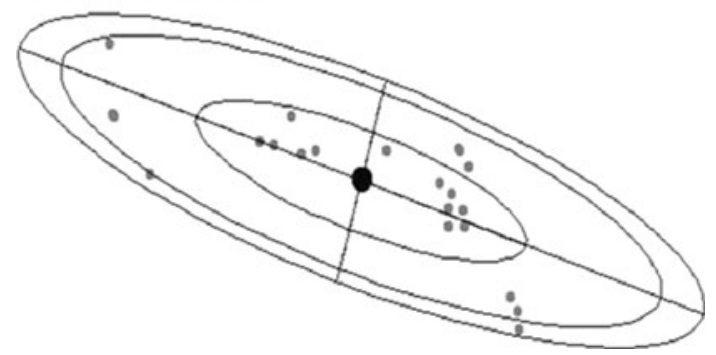

Fig. 1 Spatial properties of the herd varied when forest buffaloes were in different habitat types. The structure of the herd was defined by three tolerance ellipses (E95, E90, and E50) using the JennrichTurner method. a The size of the area used by the group was large and more rounded and $b$ the size of the area used by the group was smaller and elongated. The grey dots represent the single individual buffaloes for clearing and the beds for forest sites. This figure represents an example of herd structure independently by the sex and age of the individuals

distributed within the herd when resting in the forest $\left(\mathrm{J}_{\text {forest }}: \overline{\mathrm{x}}=0.61 \pm 0.64\right)$.

Positional preference of individuals within the herd when resting

We observed that individual positions within the herd varied with individual age/sex classes (Fig. 2). Only adult male $(\mathrm{n}=24)$ in the herd dominated the central position $\left(v^{2}=10.67, \mathrm{df}=1, \mathrm{P}=0.001, \mathrm{n}=20\right.$; Fig. 2$)$ and was observed at the periphery only four times. Females showed less positional preference, and $\left(\mathrm{v}^{2}=44.60, \mathrm{df}=2\right.$, $\mathrm{P}=0.0001, \mathrm{n}=80)$, they occupied intermediate $(\mathrm{n}=57)$, peripheral $(\mathrm{n}=14)$ and central positions $(\mathrm{n}=9)$ within the group (Fig. 2). Juveniles $\left(\mathrm{v}^{2}=38.37\right.$, $\mathrm{df}=2$, $\mathrm{P}=0.0001, \mathrm{n}=77)$, also occurred in intermediate $(n=64)$ and peripheral positions $(n=13$; Fig. 2). The $n$ value for the only adult male corresponds to the number of clearings resting places because he was always observed in this habitat type. On the contrary, the $n$ values for females and juveniles are greater than male simply because they are more numerous. 


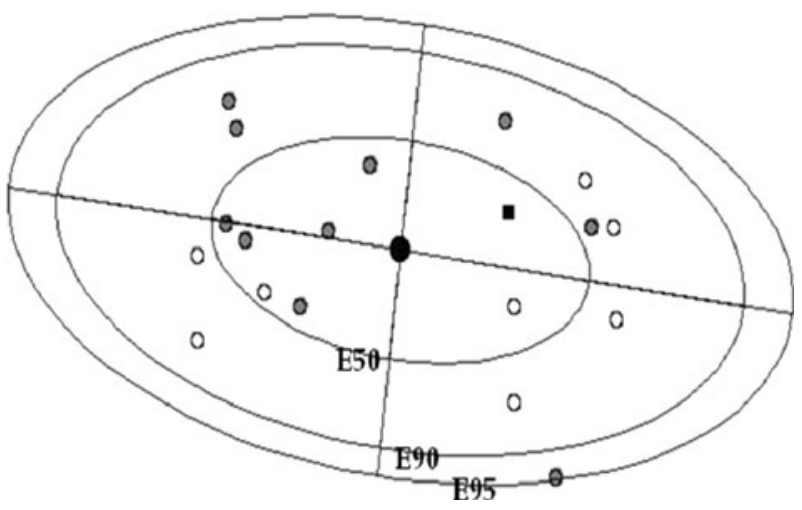

Fig. 2 An example of typical positions of individuals within the herd in clearing habitat. The different isolines, representing the three tolerance ellipses of the Jennrich-Turner estimator, were used to classify the position of individuals within the herd. The buffalo male (black square) in most cases occupied the central places of the group, whereas females (grey dots) and juveniles (white dots) were mainly observed on the edge of the group

There was little evidence that season or habitat had an effect on the number of individuals occupying each position within the herd (all P [ 0.1).

\section{Discussion}

Many physical factors structure animal groups (Krause and Ruxton 2002), and our results suggest that spatial aggregation patterns of the forest buffalo herd varied with habitat type (Fig. 1) and season. The herd tended to cover larger areas, with a shape more rounded, in open clearing habitat than in the forest (Fig. 1). In the clearings, buffaloes within the group adopted an aggregated spatial pattern, even though the herd covered a larger area. Our results are however likely to be robust to changes in the details of the herd structure when animals are foraging.

There are several key factors determining the costs and benefits of animal aggregation (Hirsch 2007). The trade-off between these costs and benefits can be a major strength determining the spatial properties of animal groups (e.g., Parrish and Edelstein-Keshet 1999; Ebensperger et al. 2006; Hirsch 2007; Morrell and James 2008). For example, previous studies have demonstrated that two of the most important factors influencing animal group size (the number of individuals in the group) and density are the presence of effective mechanisms for reducing predation (Krause and Ruxton 2002; Ioannou et al. 2007), and feeding competition (reviewed in Hirsch 2007). Studies of various species have shown that under conditions of increasing predation risk, animals form larger and denser groups (Spieler 2003; Hoare et al. 2004). Korte (2008b) found unusually high number of observations of old buffaloes and this suggests probably low predation pressure on adult while food resources probably influenced group size more than predation. Moreover, there is some evidence that feeding competition can simultaneously have a dilution effect, increasing the overall distance among individuals within a group to decrease foraging interference (Wrona and Jamienson 1991; Parrish and Hamner 1997; Krause and Ruxton 2002). For example, herds of savannah buffalo are composed by females, juveniles and some males, and smaller herds of bulls called "bachelor" groups (Sinclair 1977; Prins 1996; Cross et al. 2005). Bachelor herds use more riverine and less open habitats than mixed herds, being in this case the pattern of sexual segregation also reflected in habitat segregation, and determining the size of different herds (Hay et al. 2008). Sexual segregation has also been observed in other ungulates (e.g., bighorn sheep; Ruckstuhl 1998; Ruckstuhl and Neuhaus 2000; Ruckstuhl and Kokko 2002). On the contrary, as evidenced in previous studies (Melletti et al. 2007a, b; Korte 2008b, 2009) forest buffalo herds live in quite stable groups and members are mainly permanent part of it. In this 2 years study the male was always observed inside the herd. In another forest buffalo study (Korte 2008b, 2009) males showed a similar pattern even if sometimes were observed as lone individuals but they were never observed as bachelor groups. Similar observations have been obtained by Neuhaus and Ruckstuhl (2002) in Plains zebra (Equus burchelli) which also live in stable mixed-sex groups.

Though it is widely recognized that several important factors influence animal group size and density, less attention has been paid to those variables that affect the shape and spatial structure of the group. Our results show that habitat structure influenced group cohesion. These results are consistent with studies that have demonstrated that the group size of some mammal species inhabiting a variety of habitats can increase in more open habitat (Lagory 1985; Gerard et al. 1993, 2002; Gerard and Loisel 1995; Lingle 2003; Melletti et al. 2007a; Korte 2008b). For a typical grazer, such as buffalo, clearings and savannah mosaic landscapes represent essential food resource areas that possibly influence aggregation and increase group size (Korte 2008b; Melletti et al. 2008). During the wet season, food resources seem more abundant and homogeneously distributed, and the herd has a less aggregated spatial distribution than in the dry season. Krause and Ruxton (2002) highlighted that resource distribution is one of the most important factors affecting an individual's decision within a group. When food abundance is such that the entire group is satiated, there is no competition within the group (Hirsch 2007). Under these conditions there may be a natural sorting of individuals between the periphery and the centre of the herd, as a function of previous foraging events. This sorting could lead to larger group sizes (Krause and Ruxton 2002) with lower densities. We observed that buffalo herd 
members distributed themselves in a more aggregated spatial pattern when resting in clearings than in the forest. In the rainforest this arrangement was probably determined by forest structure, which comprised dense bushes, dead trees, and liana tangles, making it difficult for the animals to aggregate. In more uniform open grassy habitat (i.e., clearings), individuals were able to distribute in more aggregated patterns when resting.

These differences in spatial habitat structure could also influence the shape of the herd, which we observed to be more rounded in open habitat (Fig. 1a). This group geometry allows more individuals to occupy central positions while resting within the aggregation. Independent of local cues (i.e., habitat structure and season) we found a clear individual preference for a central position within the herd, and this was particularly evident for the only adult male (Fig. 2). When resting, the spatial geometry of the herd could also be determined by the costs and benefits of an individual's spatial position within the group (Hirsch 2007). Previous studies have, in general, reported that peripheral individuals experience greater predation risk, whereas those in the centre of the group have access to fewer food resources (e.g., Hamilton 1971; Parrish and Edelstein-Keshet 1999; Focardi and Pecchioli 2005; Morrell and Romey 2008). However, since predation on the forest buffaloes in our study was never observed, antipredator behaviour seems not a good reason that influences herd size and aggregation in open habitat in this specific case. Determining the underlying causal relationships and how individuals balance conflicting positional preferences within a group is difficult. Krebs and Davies (1981) postulated that three important factors, in combination, help to explain individual positional preference: (1) environmental differences between groups, such as feeding competition or the probability of predation; (2) individual differences in size, sex, and age; and (3) the behaviour of other individuals. Therefore, it is important to consider that many factors and their interactions may be determining the spatial position of individuals within the herd, and herd size.

Various studies have demonstrated that social behaviour (e.g., aggression and dominance hierarchies) and demographic factors can structure groups, with some individuals occupying advantageous positions (i.e., locations that increase feeding opportunities, reduce risk from predators, and enhance access to mates; reviewed in Hirsch 2007). As suggested by Hirsch (2007) in a study of food competition, we found that the adult male often occupied mainly the centre of the herd with the rest of the herd around him (Fig. 2). In contrast, females and juveniles were positioned to the edge of the herd (Fig. 2; Melletti et al. 2007a). These results are in agreement with previous results reported for other species (Hemelrijk 2000). Buffalo females and juveniles generally have metabolic and digestive capabilities different from males, because of their smaller size (Ruckstuhl and Neuhaus 2000). However, differences in hunger levels may promote a natural sorting of individuals between the centre and the edge of the group. The sorting behaviour of females and juveniles that we recorded within the herd could be the result of conflicts related to feeding and resting places (Krause and Ruxton 2002; Melletti et al. 2007a).

Our empirical study strongly supports the importance of habitat characteristics and social factor on the spatial properties of an animal resting group. Because animal grouping behaviour can have important effects on the spatial distribution of animal populations, a mechanistic understanding of the proximate causes underlying group social behaviours is critical to the understanding of many fundamental ecological processes.

Acknowledgments We thank the Director of the Dzanga-Shanga Project and his staff. Particular thanks go to F. Maisels, A. Turkalo, A. Todd, C. Oertle, D. Renner, L. Steel, L. Korte, G. Schwarzer, A. Bruckman, Any, and the Dzanga-Ndoki National Park Guards and WWF staff in Bangui. Many thanks to the Bai-Hokou staff and the BaAka trackers for their support during the study period. We are grateful to I. Krugersberg for useful comments on manuscript. M.M. thanks his family for their constant support during the stay in Africa. A special thanks to C. Cipolletta and D. Greer for assistance throughout the study. Thanks to G. Tortellini and L. Rossi Melletti for their moral support in the past years. This paper is dedicated to the memory of Benzino, Mokoko, and David (BaAka trackers), whose support was crucial during the field work.

\section{References}

Altmann J (1974) Observational study of behavior: sampling methods. Anim Behav 49:227-267

Beecham JA, Farnsworth KD (1999) Animal group forces resulting from predator avoidance and competition minimization. J Theor Biol 198:533-548

Blom A (2001) Ecological and economic impacts of gorilla based tourism in Dzanga-Sangha, Central African Republic. $\mathrm{PhD}$ Thesis, Wageningen University, The Netherlands

Blom A, Almasi A, Heitkönig IMA, Kpanouand JB, Prins HHT (2001) A survey of the apes in the Dzanga-Ndoki National Park, Central African Republic: a comparison between the census and survey methods of estimating the gorilla (Gorilla gorilla gorilla) and chimpanzee (Pan troglodytes) nest group density. Afr J Ecol 39:98-105

Chesson P (2000) Mechanisms of maintenance of species diversity. Annu Rev Ecol Syst 31:343-366

Cross PC, Lloyd-Smith JO, Getz WM (2005) Disentangling association patterns in fission-fusion societies using African buffalo as an example. Anim Behav 69:499-506

Ebensperger LA, Hurtado MJ, Ramos-Jiliberto R (2006) Vigilante and collective detection of predators in Degus (Octodon degus). Ethology 112:879-887

Focardi S, Pecchioli E (2005) Social cohesion and foraging decrease with group size in fallow deer (Dama dama). Behav Ecol Sociobiol 59:84-91

Fragazy DM, Boinski S, Whipple J (1992) Behavioural sampling in the field: comparison of individual and groups sampling methods. Am J Prim 26:259-275 
Gerard JF, Loisel P (1995) Spontaneous emergence of a relationship between habitat openness and mean group size and its possible evolutionary consequence in large herbivores. $\mathrm{J}$ Theor Biol 176:511-522

Gerard JF, Richard-Hansen C, Maublanc ML, Bideau E (1993) Probable exaptation within the "distributed" herd. Terre Vie Rev Ecol A 48:239-248

Gerard JF, Bideau E, Maublanc ML, Loisel P, Marchal C (2002) Herd size in large herbivores: encoded in the individual or emergent? Biol Bull 202:275-282

Grear JS, Schmitz OJ (2005) Effect of grouping behavior and predators on the spatial distribution of a forest floor arthropod. Ecology 86:960-971

Gueron S, Levin SA, Rubenstein DI (1996) The dynamics of herds: from individuals to aggregation. J Theor Biol 182:85-98

Hamilton WD (1971) Geometry for selfish herd. J Theor Biol 31:295-311

Hay CT, Cross PC, Funston PJ (2008) Trade-offs of predation and foraging explain sexual segregation in African buffalo. J Anim Ecol 77:850-858

Hemelrijk CK (2000) Sexual attraction and inter-sexual dominance. In: Moss S, Davidsson P (eds) Multi agent based simulation. Second International Workshop on Multi Agent Based Simulation. Springer, Berlin, pp 167-180

Hirsch BT (2007) Cost and benefits of within-group spatial position: a feeding competition model. Q Rev Biol 82:9-27

Hoare DJ, Couzin ID, Godin JGJ, Krause J (2004) Context-dependent group size choice in fish. Anim Behav 67:155-164

Hooge PN, Eichenlau B (1997) Animal movement extension to arcview. ver. 1.1. Alaska Biological Science Center, U.S. Geological Survey, Anchorage

Ioannou CC, Krause J (2008) Searching for prey: the effects of group size and number. Anim Behav 75:1383-1388

Ioannou CC, Tosh CR, Neville L, Krause J (2007) The confusion effect-from neural networks to reduced predation risk. Behav Ecol 2:126-130

Jennrich RI, Turner FB (1969) Measurement of non-circular home range. J Theor Biol 22:227-237

Korte L (2008a) Habitat selection at two spatial scales and diurnal activity patterns of adult female forest buffalo. J Mammal 89:115-125

Korte L (2008b) Variation of group size among African buffalo herds in a forest-savanna mosaic landscape. J Zool 275:229-236

Korte L (2009) Herd-switching in adult female African forest buffalo Syncerus caffer nanus. Afr J Ecol 47:125-127

Krause J, Ruxton GD (2002) Living in groups. Oxford University Press, UK

Krebs JR, Davies NB (1981) An introduction to behavioral ecology. Blackwell Scientific, Oxford

Lagory KE (1985) Habitat, group size, and the behavior of whitetailed deer. Behavior 98:168-179

Lingle S (2003) Group composition and cohesion in sympatric whitetailed deer and mule deer. Can J Zool 81:1119-1130

Magurran AE (1993) Individual differences in fish behavior. In: Pitcher TJ (ed) Behavior of teleost fishes. Chapman \& Hall, London, pp 441-477

MCcullagh P, Nelder JA (1989) Generalised linear modelling. Chapman \& Hall, London

Melletti M (2008) Habitat use and behaviour of forest buffalo (Syncerus caffer nanus) in Dzanga-Ndoki National Park, Central African Republic. PhD Dissertation, University of Rome "La Sapienza", Italy

Melletti M, Penteriani V, Mirabile M, Boitani L (2007a) Some behavioral aspects of forest buffalo (Syncerus caffer nanus): from herd to individual. J Mammal 88:173-179
Melletti M, Penteriani V, Boitani L (2007b) Habitat preferences of the secretive forest buffalo (Syncerus caffer nanus) in Central Africa. J Zool 271:178-186

Melletti M, Penteriani V, Mirabile M, Boitani L (2008) Effects of habitat and season on the grouping of forest buffalo resting places. Afr J Ecol 47:121-124

Melletti M, Mirabile M, Penteriani V, Boitani L (2009) Habitat use by forest mammals in Dzanga-Ndoki National Park, Central Africa Republic. Afr J Ecol 47:797-800

Mloszewski MJ (1983) The Behavior and Ecology of the African Buffalo. Cambridge University Press, Cambridge

Morrell LJ, James R (2008) Mechanism for aggregation in animals: rule success depends on ecological variables. Behav Ecol 19:193-201

Morrell LJ, Romey WL (2008) Optimal individual positions within animal groups. Behav Ecol 19:909-919

Neuhaus P, Ruckstuhl KE (2002) The link between sexual dimorphism, activit budgets and group cohesion: the case of the plains zebra (Equus burchelli). Can J Zool 80:1437-1441

Parrish JK, Edelstein-Keshet L (1999) Complexity, pattern, and evolutionary trade-offs in animal aggregation. Science 28:99-101

Parrish JK, Hamner WM (1997) Animal groups in three dimensions. How species aggregate. Cambridge University Press, Cambridge

Perry JN (1995a) Spatial aspects of animal and plant distribution in patchy farmland habitat. In: Glen D, Greaves M, Anderson HM (eds) Ecology and integrated arable farming systems. Wiley, Chichester, pp 221-242

Perry JN (1995b) Spatial analysis by distance indices. J Anim Ecol 64:303-314

Perry JN (1998) Measure of spatial pattern for counts. Ecology 79:1008-1017

Perry JN, Bell ED, Smith RH, Woiwood IP (1996) Sadie: software to measure and model spatial pattern. Appl Biol 46:95-102

Perry JN, Winder L, Holland JM, Alston RD (1999) Red-blue plots for detecting clusters in count data. Ecol Lett 2:106-113

Prins HHT (1996) Ecology and behavior of the African buffalo. Social inequality and decision making. Chapman \& Hall, London

Rands SAR, Pettifor A, Rowcliffe JM, Cowlishaw G (2006) Social foraging and dominance relationships: the effects of socially mediated interference. Behav Ecol Sociobiol 60:572-581

Ruckstuhl KE (1998) Foraging behaviour and sexual segregation in bighorn sheep. Anim Behav 56:99-106

Ruckstuhl KE (1999) To synchronise or not to synchronise: a dilemma for young bighorn males? Behaviour 136:805-818

Ruckstuhl KE, Festa-Bianchet M (2001) Group choice by subadult bighorn rams: trade-offs between foraging efficiency and predator avoidance. Ethology 107:161-172

Ruckstuhl KE, Kokko A (2002) Modelling sexual segregation in ungulates: effects of group size, activity budgets and synchrony. Anim Behav 64:909-914

Ruckstuhl KE, Neuhaus P (2000) Sexual segregation in ungulates: a new approach. Behavior 137:361-377

Sinclair ARE (1977) The African buffalo. University of Chicago Press, Chicago

Spieler M (2003) Risk of predation affects aggregation size: a study with tadpoles of Phrynomantis microps (Anura: Microhylidae). Anim Behav 65:179-184

Sumpter DJT (2006) The principles of collective animal behavior. Philos Trans Roy Soc B 361:5-22

Turkalo A, Fay JM (2001) Forest elephant behaviour and ecology. Observations from the Dzanga Saline. In: Weber W, White L, Vedder A, Naughton L (eds) African rain forest ecology and conservation. Yale University Press, Ithaca, pp 207-213 
Turner WC, Jolles AE, Owen-Smith N (2005) Alternating sexual segregation during the mating season by male African buffalo (Syncerus caffer). J Zool 267(3):291-299

UdeV Pineaar (1969) Observations on developmental biology, growth and some aspects of the population ecology of African buffalo (Syncerus caffer caffer Sparrman) in the Kruger National Park. Koedoe 12:29-53
Van Gils JA, Piersma T (2004) Digestively constrained predators evade the cost of interference competition. J Anim Ecol 73:386-398

Wilson DE, Reeder DM (2005) Mammals species of the world. The John Hopkins University, Baltimore

Wrona FJ, Jamienson RW (1991) Group size and predation risk: a field analysis of encounter and dilution effects. Am Nat 137:186-201 